\title{
Interface
}

\section{A AFETIVIDADE NA PRÁTICA PEDAGógICA}

\author{
Sylvio César Pereira Cidade (1)
}

\begin{abstract}
Resumo
O artigo trata da importância do afeto no processo de construção do conhecimento e na relação professor aluno. Atenta para a maneira como o fator afetividade pode influenciar positivamente na auto-estima dos discentes e na melhora da aprendizagem. Embora muitos professores procurem dar grande destaque aos conteúdos escolares e pouco ou quase nada fale dos aspectos socioemocionais, é urgente a tomada de iniciativas por parte dos pedagogos e docentes no sentido de humanizar a educação. Nessa perspectiva cabe uma reflexão sobre a necessidade de uma tomada de consciência do verdadeiro sentido da educação, que é a formação do ser social como um todo, desde a dimensão intelectual até a afetiva.
\end{abstract}

Palavras-Chave: Pedagogia; afeto; auto-estima; aprendizagem.

Uma das autoras que melhor comenta sobre a afetividade é Rossini (2001), que nos orienta que a afetividade acompanha o ser humano desde o nascimento até a morte. Ela estaria em nós como uma fonte geradora de energia. Segundo Piaget "parece existir um estreito paralelismo entre o desenvolvimento afetivo e o intelectual, com este último determinando as formas de cada etapa da afetividade" (PIAGET, 1962, p. 158), mas o que se observa hoje em dia é que a afetividade é a base sobre a qual se constrói o conhecimento racional.

As crianças que possuem uma boa relação afetiva são seguras, têm interesse pelo mundo que as cerca, compreendem melhor a realidade e apresentam melhor desenvolvimento intelectual. 
A educação tem como objetivo o pleno desenvolvimento do educando e o preparo para o exercício da cidadania, isso é o que reza a atual lei de Diretrizes e bases da educação Nacional (LDBEN 9394/93, Art. $2^{\circ}$ p. S). entretanto vários aspectos vem contribuindo para dificultar o bom rendimento do educando e que muitas vezes resulta do reflexo de uma fragilizada auto-estima.

Um desses aspectos sobre o qual nossa análise se concentra trata das relações estabelecidas entre o professor e o aluno no ambiente pedagógico. Por isso, é necessária a reavaliação de determinadas posturas e tomadas de atitude, adotadas pelo professor, que dificultam ou bloqueiam o aprendizado do aluno.

É certo que o papel da escola é o de otimizar o processo de ensino-aprendizagem a partir da utilização de metodologias eficazes e que sejam próprias a cada realidade de sala de aula. Com tamanha diversidade de conhecimentos e levando em conta a heterogeneidade de alunos somente um bom planejamento talvez não seja suficiente para atingir os objetivos, mas sim a forma voluntariosa e agradável com a qual se transmite os conteúdos, a emoção e o afeto passam a fazer a diferença no plano pedagógico. Sobre isso, considera Miranda (2005),

(...) é belo o oficio de educar: são eles os nossos alunos, que, dando continuidade às gerações que se sucedem, conduzem adiante a fulgante tocha do conhecimento. Mas nós somos os seus professores, os guias dos seus passos na qualidade de seres aprendentes que são ofertando-lhes com ternura e alegria, o melhor de que dispomos como elementos necessários aos seus incrementos intelectuais, morais, culturais e emocionais (...)

(...) somos seus companheiros, sim. Mas somos, principalmente, timoneiros de uma vibrante e rica jornada que os levará ao porto seguro da realização pessoal e profissionais, ao compromisso inesgotável de defenderem um mundo em que caibamos todos, em condições iguais. E com direito ao incansável jargão: "mais justo, mais humano, mais alegre e mais afetivo”. (...) somos ao mesmo tempo, educadores de espírito, engenheiros de sonhos e arquitetos de utopias (MIRANDA, 2005, p.16).

Um dos meios para tentar-se alcançar os objetivos traçados durante o planejamento é a criação de vínculos com os alunos e para tanto é necessário que o professor faça uma observação atenta dos mesmos. O objetivo dessa observação é efetuar o colhimento de forma 
ordenada de um maior número de informações sobre o educando, tais como: saúde, inteligência, rendimento e psicomotricidade.

Dentro desse contexto o equilíbrio emocional é de grande importância para o mestre, devendo este buscar ampliar seus conhecimentos de Psicologia para que possa compreender melhor as atitudes dos seus alunos, analisar o comportamento e traçar o perfil de cada um com maior segurança objetivando procurar ajudá-los quando necessário.

Segundo Márcio Ferrari (2004, p.36),

"O ensino tem como função principal, levar as crianças a desenvolver as suas habilidades naturais. $O$ desenvolvimento dessa habilidades ocorre mais facilmente nas séries iniciais nas quais a relação entre docentes $e$ discentes precisa ser mostrada por um maior grau de afetividade. $O$ processo de conquista dos alunos envolve uma série de procedimentos didáticos e extra-didáticos e muitas vezes pode levar bastante tempo. Geralmente uma conversa agradável dentro ou fora da sala de aula, o uso de dinâmicas, de jogos interativos, a própria aproximação com os pais dos alunos podem contribuir decisivamente na criação de maiores vínculos entre ambos.

Normalmente o aluno faz do ambiente escolar uma extensão do seu lar, sendo assim ele busca na escola segurança e afeto. Dessa forma, toda a equipe pedagógica precisa estar preparada para lidar com isso.

Para muitos pedagogos e professores não existe educação sem amor, são seguidores do pensamento de Paulo Freire. Deve haver a disponibilidade para a alegria e para o afeto. É evidente que nessa forma de agir e pensar o aspecto da afetividade não significa a existência de uma espécie de pacto, cumplicidade entre professor e aluno no tocante ao favorecimento ilícito através da concessão de notas ou conceitos sem que o discente tenha atingido as metas as quais lhe são propostas.

Ao contrário, a Pedagogia da afetividade pretende utilizar os mecanismos e ferramentas da Psicologia que possam subsidiar uma maior aproximação humana com vistas a estreitar cada vez mais os laços que unem professores e alunos. Segundo Freire, citado por Snyders (1993), 
(...) gerando-se numa alegria mais a alegria de viver - a alegria na escola fortalece e estimula a alegria de viver. Se o tempo da escola é um tempo de enfado em que o educador e educadora e educando vivem os segundos, os minutos, os quartos de hora à espera de que a monotonia termine a fim de que partamos para a vida lá fora, a tristeza da escola termina por deteriorar a alegria de viver (SNYDERS 1993, p. 9)

Ao professor requer perceber em cada um dos seus alunos as potencialidades e talentos. É importante o conhecimento das histórias de vida e a criação de condições para se tenha um ambiente alicerçado numa relação de confiança. A conquista dessa confiança, por parte do professor, abre perspectiva para um novo horizonte no processo de ensinoaprendizagem, pois passa a fundamentar-se em doses equilibradas de razão e sensibilidade.

Atitudes como chamar o aluno pelo nome ou mesmo demonstrar interesse nos problemas que afligem-no são eles que podem servir de aproximação entre o educador e o educando. Muitas vezes o professor cumpre na prática uma missão que vai além de ensinar os conteúdos. Dependendo do nível de aproximação entre este e o seu aluno, do grau de confiança depositado por este último no seu professor pode ser estabelecida uma ampla relação de amizade.

No contexto atual de educação é de suma importância que a escola busque ter um comprometimento não apenas com o desenvolvimento cognitivo do aluno, mas sobretudo com o seu desenvolvimento sócio-emocional. Na realidade, a criança quando chega à escola já trás consigo uma bagagem de vivências, anterior ao período escolar, que vai refletir-se em suas atividades cotidianas. O professor da mesma forma, também tem suas experiências anteriores. Do sucesso da interação entre essas duas personalidades dependerá a formação da criança e sua evolução em termos de aprendizagem. Consciente de que seu papel é primordial neste processo educativo, o professor angustia-se muitas vezes sem saber como ou por onde começar.

Não raras as vezes em que professores e orientadores pedagógicos têm dificuldades em se colocar como agentes facilitadores de uma aprendizagem afetiva e efetiva, ou seja, positiva em relação aos alunos. Augusto Cury não hesita em afirmar que as escolas da Pedagogia falham por não estimularem os seus professores a se humanizarem em sala de aula. E coloca a necessidade de se humanizar o conhecimento e primordialmente fazer o mesmo com os mestres. 
O ambiente escolar cujos professores buscam a cada dia se humanizarem mais precisa ser um ambiente alegre, onde todos se sintam bem. Ser alegre na escola implica dar um sentido a vida, mostrar os motivos que fazem valer a pena a realização dos estudos, buscar e encontrar motivos para fazer com que as pessoas sintam-se especiais e insubstituíveis. É preciso interagir com os alunos também no campo da emoção, ensinar vibrando com entusiasmo e paixão pelo ser humano. Uma escola saudável e alegre é aquela onde o professor dar valor a si, ao seu aluno, bem como a própria instituição.

O mestre precisa ser movido pela crença de que o processo pedagógico baseia-se no amor e no afeto. Não pode-se conceber separar o ser intelectual do emocional. Apesar de a sociedade atual ser marcada pelo ativismo, racionalismo, pelas exigências de qualidades intelectuais cada vez maiores e pela dinâmica informacional, ela não deve relegar a segundo plano um dos aspectos mais íntimos do ser humano, aquilo que lhe confere uma identidade, uma característica que é a emoção.

Vygotsky (1996) acreditava que um dos principais defeitos da psicologia tradicional é a separação entre os aspectos intelectuais e os volitivos e afetivos propondo ser considerado a unidade entre esses dois elementos. Ele explica que a origem do pensamento é na esfera da motivação, a qual inclui inclinações, necessidades, interesses, impulsos, afeto e emoção.

A aprendizagem deve ser fundamentada em um bom relacionamento inter-pessoal entre todos os membros que participaram desse processo. A interação professor-aluno é essencial tendo que ser cultivada nas dimensões do afeto e dos limites. A tarefa do mestre vai vislumbrar novos desafios a cada dia na medida em que o seu nível de envolvimento com o aluno aumente, assim podemos supor que para o professor todos os alunos são importantes e o grande objetivo passa a ser: descobrir a melhor forma de ajudá-los a evoluir como aluno e como pessoa.

Piaget (1962) propõe que existe um estreito paralelismo entre o desenvolvimento da afetividade e das funções intelectuais e que nenhum ato é puramente intelectual nem puramente afetivo, mas é inegável que a afetividade tem um papel importantíssimo no desenvolvimento da criança.

A teoria psicogênica Walloniana (WALLON, 1986) destaca o fator afetividade como fundamental no processo de desenvolvimento humano. A educação, portanto, é condição formadora necessária ao desenvolvimento natural do indivíduo sob o qual está assentada toda uma base emocional onde o papel do professor é de grande relevância. 
A partir do momento em que o aluno percebe que é importante para o professor , que é valorizado pelo que é ou pelo que aparenta ser sua visão de mundo pode começar a mudar.

Não é interessante que o aluno, na prática, não passe de um mero número relacionado no diário do professor ou nos livros e arquivos da secretaria. Talvez aquilo que o aluno mais deseja é ser percebido como alguém que possui uma história, sentimentos, sonhos e uma identidade. $\mathrm{O}$ ambiente escolar deve ser prazeroso, o lugar onde os alunos possam buscar o apoio necessário ao seu desenvolvimento. É imprescindível diluir-se a vertente ideológica que coloca a escola como um ambiente de prisão e punição. O caráter punitivo, talvez ainda herdado de uma escola tradicional secular, pautado na falta de diálogo e na imposição de tipos de conduta deve ser substituído por um caráter de amizade e participação das decisões de interesse comum.

A missão do profissional da educação passa a ser cada vez mais valorizada ao passo em que ele mesmo nutre no seu aluno uma auto-estima positiva e mostra-o que é capaz de superar as limitações.

Augusto Cury (2003) diz que a tarefa mais importante da educação é transformar o ser humano em líder de si mesmo, líder dos seus pensamentos e emoções.

Entendemos que uma das maneiras de educar a auto-estima do aluno é elogia-lo antes de fazer a crítica. Cury (2003, p.143) ainda afirma: O elogio alivia as feridas da alma, educa a emoção e a auto-estima, elogiar é encorajar e realçar as características positivas. Há pais e professores que nuca elogiaram seus filhos e alunos. Dessa forma, parece que o elogio no momento correto, causa uma sensação de satisfação, de prazer. A política do elogio quando bem administrada eleva a auto-estima que por sua vez serve como combustível para o enfrentamento de novos desafios. O estímulo trata-se de uma atitude positiva que leva a uma outra.

Na dimensão da pedagogia afetiva muitas variáveis entram no processo de ensinoaprendizagem: a capacidade intelectual e vontade de aprender pelo lado do aluno; os conhecimentos e a capacidade de transmitir conteúdos, pelo lado do professor. Somando-se essa duas vertentes fica estabelecida uma ligação entre as partes que rompe uma simples idéia de contrato para configurar uma relação fraternal. Nesse panorama no acompanhamento dos processos pedagógico, sobretudo no devido suporte a eles.

Fazer os educandos sentirem-se melhor, motivados para o estudo e para a vida, mais confiantes nas suas potencialidades, essa é uma atribuição do professor. É preciso que o educando tenha em mente de forma bem clara aquilo que pretende alcançar, cabendo ao 
professor mostrar os caminhos que podem ser trilhados. Destaca-se aqui a importância do educador enquanto facilitador do processo ensino-aprendizagem A boa qualidade do diálogo entre docente e discente pode fazer a diferença.

O professor motivado faz o aluno aprender. O mais importante no processo de conquista do aluno, por parte do professor, consiste no fato de o educador deixar claro para o educando o quanto é importante, mesmo que não aparente ou que alguém ainda não o tenha dito.

Muitos mestres procuraram tomar conhecimento das procedência do aluno descobrir com quem mora o que costuma fazer nos momentos em que não está na escola, os programas de tv que assiste entre outras coisas. Até mesmo os alunos ditos problemáticos, indisciplinados mudam o seu comportamento durante as aulas dos professores com os quais mais costumam dialogar. Paulo Freire (1985, p.25) afirma:

Todavia, existe algo que deve ser destacado. Na medida em que o compromisso não pode ser um ato passivo, mas práxis-ação e reflexão sobre a realidade -, inserção nela, ele aplica indubitavelmente o conhecimento da realidade. O compromisso só é válido quando está carregado de humanismo (...)

O comprometimento passa pela doação. Não se pode "planejar a afetividade". Ela parte do íntimo de cada um e se manifesta pela ação concreta no campo pedagógico. Num ambiente no qual a afetividade é "marca registrada" provavelmente sairão pessoas capazes de lidar com seus sentimentos o que contribuirá para uma sociedade mais justa, saudável e menos agressiva.

O processo de ensino-aprendizagem trata também da construção de um ideal de vida muito embora grande parte dos educadores talvez não tenham ainda atentado para isto e, portanto, não colocam essa perspectiva para os seus alunos.

A tentativa de transmitir conhecimentos sistematizados sem que haja a preocupação de lhes dar um significado concreto e que se aproxime da realidade dos educandos acaba tirando possibilidades de um melhor aproveitamento dos assuntos trabalhados durante as aulas.

O tempo de uma aula não pode ser desperdiçada, mas sim ser amplamente aproveitada no âmbito da realização de discussões positivas e que interessem para a realidade na qual os alunos estão inseridos. O educando não pode ser visto e tratado como um receptor 
de informações as quais a qualquer instante podem ser cobradas através de um tipo qualquer de avaliação. Ao contrário são eles pessoas cujo campo emocional pode estar ou não em equilíbrio. Enxergar o educando com os olhos da afetividade é saber o que ensinar, por que, para que e a ocasião conveniente.

Os sentimentos e as emoções do aluno precisam ser sempre levados em consideração, pois podem favorecer ou não o desenvolvimento cognitivo.

Na visão de Rossini (2001) o desenvolvimento da afetividade está alicerçado sobre três pontos básicos: nos limites, nos mitos do cotidiano e nos ritmos. No plano dos limites é importante mostrar aos alunos que eles não podem nem são capazes de fazer tudo o que querem e que o estabelecimento de regras são importantes na medida em que o respeito a elas motiva outras pessoas a também respeitá-las de forma a promoverem ambientes saudáveis e construtivos.

Já os mitos do cotidiano consistem nas tradições, às vezes lendárias ou não, que mostram os principais acontecimentos da vida. A forma com as quais o professor trabalha com seus alunos visando o enfrentamento das mais diversas situações que acontecem ou que podem vir a acontecer em sala de aula ou mesmo no ambiente extra-escolar. A capacidade de solucionar problemas ou conflitos é um tipo de habilidade que precisa ser desenvolvida no meio escolar por meio de estudos e leituras que contemplam o que a Psicologia chama de inteligência emocional.

Alunos que conseguem desenvolver a capacidade afetiva tratam com amor e aplicação as suas atividades escolares cotidianas. Não se trata de um cumprimento formal dos deveres os quais lhes são atribuídos pelas convenções sociais, mas sobretudo de uma possibilidade de compreensão da própria sociedade onde vive.

O ambiente escolar deve ser um grande teatro de espetáculos onde professores e alunos possam brilhar como astros maiores, onde as acertos sejam bem valorizados e os erros sirvam para momentos de reflexão e de fortalecimento interior para o enfrentamento de novos desafios. Não se deve enaltecer e ofuscar o brilhantismo dos acertos pelo fatalismo dos erros cometidos. É comum a existência de comparações numa sala de aula onde os próprios alunos - e também o professor - criam uma hierarquia entre eles onde podem figurar os melhores e os piores. Entre os primeiros, os mais estudiosos, e os últimos, ou seja a parte que tira notas baixas e/ou não demonstra o menor interesse pelas aulas.

A princípio é importante que o professor procure se aproximar dos alunos cujo rendimento é baixo e saber por que isso ocorre. As causas são variadas podendo ser um problema familiar que cause uma instabilidade emocional, ou mesmo uma causa física, como 
por exemplo uma deficiência na visão. Muitas vezes o professor é o único apoio com o qual os alunos podem contar.

Embora o professor por seu grande conhecimento sobre a matéria a qual leciona talvez o mais importante é a maneira como ele estabelece relações de afetividade com os alunos. A prática pedagógica deve buscar uma vivência humanizadora que seja capaz despertar em cada indivíduo a vontade de se superar, de romper os seus limites.

O desenvolvimento da habilidade emocional é a grande coluna que sustenta a educação. Trabalhar com indivíduos que não possuem a auto-valorização constitui um grande desafio a ser superado tanto pelo aluno quanto pelo professor. O desânimo e a falta de motivação podem não ser reflexo unicamente de aulas monótonas, sem atrativo, mas também pela inexistência de uma estrutura familiar sólida. Trabalhar na dimensão da emoção é um exercício contínuo de aprendizado, de lhe dar ganhos e perdas.

Numa sociedade marcada pelas desigualdades sociais e pela violência, a responsabilidade dos educadores aumenta significativamente, pois educar significa também formar para a vida, para o bom convívio social. Mas o compromisso deve ser assumido do anteriormente pela família das crianças e jovens para que a escola possa dar continuidade.

O professor precisa estar revestido de amor para que possa então converte-lo aos seus alunos, que por sua vez deverá cultivá-lo onde quer que vá.

Sobre o assunto, Rossini (2003, p.44) disserta:

A complexidade da vida moderna acaba delegando aos professores papéis antes só de responsabilidade dos pais. A família de hoje conta muito com a escola, ou seja com seus professores na formação das crianças e dos jovens. Ela precisa estar informada sobre a linha de conduta que a escola tem para com seus filhos e, o que é fundamental, concordar com esta linha: é preciso falar a mesma língua. Nos dia de hoje, o professor deve ser um “líder”. Deve saber que liderança não se impõe, se conquista.

$\mathrm{Na}$ sala de aula, ele representa a direção, a própria família. Ali ele é o “dono da lei". Deve ter qualidades humanas imprescindiveis num educador de hoje: equilíbrio emocional, responsabilidade, caráter, alegria de viver, ética e principalmente gostar de ser professor. 


\section{Conclusão}

A maioria das escolas brasileiras priorizar o cumprimento da sua grade curricular e o desenvolvimento cognitivo. O objetivo central é preparar o aluno para o vestibular passando muitas vezes a idéia de que esse é o fim mais importante da educação.

Diante desse contexto a educação mais humanista fica nublada e às margens dos projetos pedagógicos mais importantes dentro das escolas.

Tal como foi dito a educação objetiva o pleno desenvolvimento do educando, mas a emoção humana não tem sido objeto da atenção de muitos educadores.

O presente artigo pretendeu apoiado sob o ponto de vista da Psicologia, oferecer algumas contribuições para o desempenho do trabalho do professor em sala de aula.

Espera-se que possam ser de muita valia para subsidiar a prática docente.

\section{Referências}

BRASIL, Mec. Lei de Diretrizes e Bases da Educação. Lei no 9394 de 20/12/2006. ed. RC. Recife. 1997

CURY, Augusto (2003). Pais brilhantes e professores fascinantes. Rio de Janeiro. Ed. Sextante vigoisky Fonte: internet

FERRARI, Márcio. O teórico que incorporou o afeto à pedagogia. In: Revista Nova escola, Abril/2007

FREIRE, Paulo (1985). Educação e Mudança. Rio de Janeiro. Ed. Paz e Terra.

MIRANDA, de Simão (2005). Professor, não deixe a peteca cair! Campinas. Papirus

PIAGET, J. A relação da afetividade com a inteligência, no desenvolvimento mental da criança. Texto retirado da internet e traduzido do original "the relation of affetivity to intelligence in the mental development of the child". Bulletin of the Menninger Clinic, London, v. 26, n. 3, 1962, V. 26, n. 3. p. 158-200, mar. 1962.

ROSSINI, Maria Augusta Sanches (2001) Pedagogia Afetiva. Petrópolis, RJ. Ed. Vozes.

SNYDERS, Georges (19936). Alunos felizes: reflexões sobre a alegria na escola a partir de textos literários. São Paulo. Paz e Terra.

SOUZA, Iracy Sá de (1969). Psicologia. A aprendizagem e seus problemas. Rio de Janeiro. Livraria José Olympio Editora. 
VIGOTSKI, Liev Semionovich. Teoria e método em psicologia. São Paulo: Martins Fontes, 1996.

WAllON, H. Psychologie et education de l'enfant. In: F. Fernandes (Coord.) Henri Wallon. São Paulo: Ática, 1986 (Originalmente publicado em 1959).

\section{Sobre o autor:}

(2) Sylvio César Pereira Cidade é Professor, Graduado em Geografia pela Universidade Regional do Cariri - URCA, com especialização em Psicologia Aplicada à Educação e, especialização em Geopolítica e História.

E-mail: cesarsylvio@ hotmail.com 